\title{
Articles
}

\section{A Study of the Potential Interference of $\mathrm{ArC}^{+}$on the Direct Determination of Trivalent Chromium and Hexavalent Chromium Using Ion Chromatography Coupled with ICP-MS}

\author{
Sang-Ho Nam, ${ }^{*}$ Young-Il Park, Jae-Jin Kim, Sun-Ho Han, ${ }^{\dagger}$ and Won-Ho Kim \\ Department of Chemistry, Mokpo National Lniversity, Mhangun, Chonnam 534-729, Korea \\ Nuclear Chemistry Research Division, Korea Atomic Energy Resecurch Institute, Daejeon 305-353, Korea \\ Received August 26, 2003
}

\begin{abstract}
Low and high resolution inductively coupled plasma mass spectrometry (ICP-MS) coupled with ion chromatography (IC) has been investigated for speciation of $\mathrm{Cr}(\mathrm{III})$ and $\mathrm{Cr}(\mathrm{VI})$. In particular. the interference of $\mathrm{ArC}^{-}$formed by the carbon in a sample on the simultaneous determination of $\mathrm{Cr}(\mathrm{III})$ and $\mathrm{Cr}$ (VI) has been studied. In chemical speciation. this study shows that quadnupole type ICP-MS with low resolution has a limitation of simultaneous determination of chromium species if the sample contains the carbon elements. The interference problems can be solved by high resolution ICP-MS.
\end{abstract}

Key Words : Chromium species. Ion chromatograply. ICP-MS

\section{Introduction}

In various research fields. the chemical speciation of trace elements in a sample has been very important because the effects of elements. especially trace heavy metals. on ecological and environmental systems are generally influenced by the elements chemical forms. ${ }^{1-3}$ Some elements in a sample not only exist in more than one valence state. but also can be present as cationic. anionic, and neutral species. In particular. $\mathrm{Cr}$ (III) is an essential element in nutrition. but $\mathrm{Cr}(\mathrm{VI})$ is very toxic to human beings. ${ }^{+}$Ion chromatography (IC) has been widely used for the chemical speciation of elements in various samples. The procedure. in general. consists of a separator colunul. a suppressor column. a conductivity detector (or UV/VIS detector). But, due to the low dissociation characteristics for conductivity detection and the poor complexation ability for UV/VIS absorption detection. some analytes have posed problem for measurement with IC. Thus, IC has been coupled with various detectors to overcome the difficulties ${ }^{+17}$ The various analytical methods were reviewed for the speciation of $\mathrm{Cr}(\mathrm{III})$ and $\mathrm{Cr}(\mathrm{VI})$. " Direct current plasma atomic emission spectrometry (DCP. $\mathrm{AES}$ ) has been used as an element selective detection method. ${ }^{4.5}$ Inductively coupled plasma atomic enission spectrometry (ICP-AES) has been coupled with chromatograply for element speciation. Side-On-View (S-O-V) ICPAES has been reported as an element selective detection method after clromatographic separation. ${ }^{6}$ According to reports, the detection limit can be low for both $\mathrm{Cr}(\mathrm{III})$ and $\mathrm{Cr}$ (VI) with hollow cathode atomic absorption spectrometry (HC-AAS) coupled with the preconcentration technique. ${ }^{8}$ Wavelength modulation diode laser flame atomic absorption spectrometry (WM-LAAS) was coupled with liquid chromatography for cluromium speciation. ${ }^{9}$ The speciation of $\mathrm{Cr}$ (III) and $\mathrm{Cr}(\mathrm{VI})$ has been done with direct-injection nebulization (DIN) and S-O-V ICP-AES. ${ }^{10}$ E-O-V ICP-AES could be also used for the detection of chromium species. ${ }^{18}$

Since plasma source mass spectrometry has been used as an element selective detector for IC, inductively coupled plasma mass spectrometry (ICP-MS) has been the most powerful tecluique for the detection of analytes separated by IC due to high detection power. multi-elemental analysis, minor matrix effect, minor memory effect, high analysis speed and the tolerance to high salt concentration. ${ }^{7.19-24}$ The speciation of arsenic in urine has been done using lighperfonmance liquid chromatography with inductively coupled plasma mass spectrometric detection. ${ }^{19-21}$ Inductively coupled plasma mass spectrometry was used for micellar liquid chromatography: speciation of alkyltin compounds."2 Liquid chromatography was combined with an inductively coupled plasma mass spectrometric detector for simultaneous determination of gold drug metabolites and related metals in human blood. ${ }^{33}$ ICP-MS was used for the detection of chromium species. ${ }^{7}$

But, in these previous studies. the interferences on the simultaneous determination of chromium species in samples with ICP-MS coupled with clromatographic methods have not been extensively studied. The $\mathrm{ArC}^{-}$formed by the carbon elements can seriously interfere with the accurate analysis of the chromium species in environmental and clinical samples. In the present study, the interference caused by $\mathrm{ArC}^{-}$on the determination of chromium species has been studied with low and high resolution ICP-MS coupled with IC. 


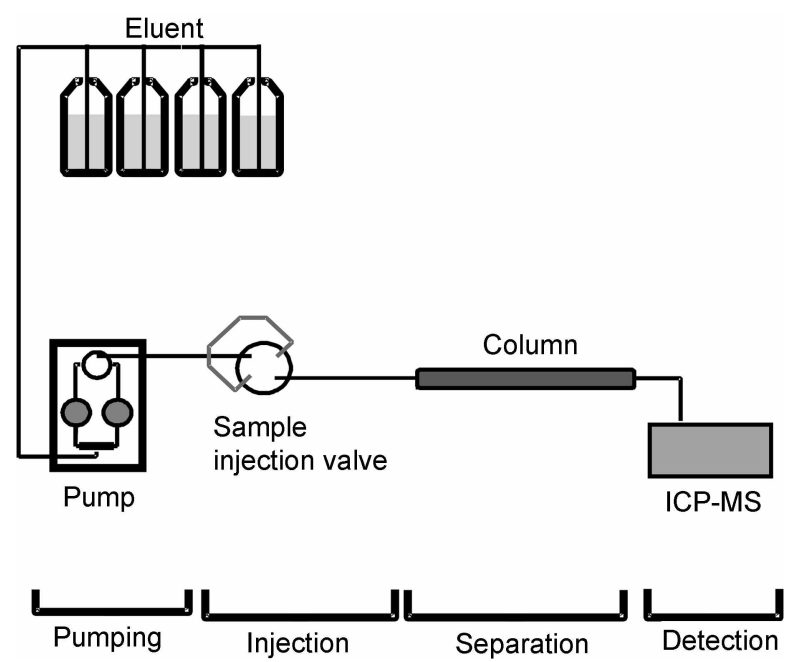

Figure 1. Schematic diagram of ICP-MS with IC.

\section{Experimental Section}

Instrumentation and operating condition. The chromatographic system used in the present work was a Dionex (Dionex Corporation, Sunnyvale, CA, 94088-3603, USA) model GP 50 ion chromatography pump. Samples were introduced into the analytical column by direct injection with a sample loop. The sample injection volume was 200 $\mu \mathrm{L}$. An analytical column ANX4605-Cr (CFTAC Technologies INC. 5600 South 42nd street, Omaha, Nebraska 68107. USA) was used. The effluent from the analytical column was introduced directly into HR-ICP-MS (Thermo Finnigan MAT, GmbH Barkliausenstr. 2, D-28197, Bremen, Germany) model Finnigan MAT FI.EMГNT. The general schematic diagram for this study is shown in Figure 1. Details of the

Table 1. Instrumentals and operating conditions

Ion chromatography

\begin{tabular}{ll}
\hline Sy'stem & GP50 Gradient Pump (Dionex Corp.) \\
Flow rate & $1.0 \mathrm{~mL}$ min \\
Analytical column & ANX 4605-Cr anion exchange column \\
& (CLEAC lechnologies) \\
Sample loop & 200 \\
LiJuent & $0.06 \mathrm{M} \mathrm{HNO}$. \\
\hline
\end{tabular}

ICP-MS

\begin{tabular}{|c|c|}
\hline System & Finnigan MAT ELEMEN'T \\
\hline Plasma power & $1300 \mathrm{~W}$ \\
\hline Outer gas flow: & Ar. $13.00 \mathrm{~L} / \mathrm{min}$ \\
\hline Auxiliaty gas flow & Ar: $0.70 \mathrm{~L} / \mathrm{min}$ \\
\hline Nebulizer gas flow & $\begin{array}{l}\text { Ar. Low resolution: } 0.70 \mathrm{~L} / \mathrm{min} \\
\text { Medium resolution: } 0.68 \mathrm{~L} / \mathrm{min}\end{array}$ \\
\hline Resolution & $\begin{array}{l}\text { Low resolution: } 300 \\
\text { Medium resolution: } 4000\end{array}$ \\
\hline Jotal acquisition time. s & 650 \\
\hline Monitoring mass & $\begin{array}{l}\text { Low resolution: miz } 51.9400 \\
\text { Medium resolution: } \mathrm{Cr}^{2} \mathrm{~m} / \mathrm{z} 51.9400 \\
\qquad \mathrm{Ar} \mathrm{C}^{\prime \prime} ; \mathrm{m} / \mathrm{51} .9618\end{array}$ \\
\hline
\end{tabular}

instru-mental and operating condition are described in Table 1.

Chemicals and reagents. Analytical stock solution for Cr(III) (ICP-ACS of stock solution $1000 \mathrm{ppm}$, in $2 \% \mathrm{HNO}_{3}$. cat. \# Pl.CR2-2Y) was obtained from SPFX Certiprep (203 Noreross Ave. Metuchen, N.I 08840, USA). Cr(VI) (Potassium Chromate $\mathrm{K}_{2} \mathrm{CrO}_{4}, \mathrm{No}_{0}$. 731692) was obtained from Fisher I aboratory (Fisher Scientific Canada. I td, $112 \mathrm{ch}$, Colonnade Road Nepean, Ontario KIT:7I 6, Canada). The eluent of 0.06 $\mathrm{MHNO}$; was prepared from concentrated nitric acid (Merck White House Station N.J 8889-0200, USA). The potassium cyanide and potassium carbonate were obtained from Merck (Merck 1.td, wsiw-53, Germany). All solutions were also prepared with $18 \mathrm{M} \Omega \mathrm{cm}$ distilled deionized water obtained from the aquaMAX ${ }^{\mathrm{MM}}$ (AQ-MAX-311BASIC(II) MГM) water purification system (Young 1.in, 899-6 Hokye 2-dong, Dongan-gu, Anyang-si, Kyounggi-do 431-836, Korea).

\section{Results and Discussion}

$\mathrm{Cr}(1]$ ) is an essential element, but $\mathrm{Cr}(\mathrm{VI})$ is very toxic to human beings. Thus, speciation of chromium ions in a sample is very important. Many studies have been done on the chemical speciation of chromium, ${ }^{1-18}$ But, the interference effects of other ions on the chemical speciation of chromium bave not been investigated. Thus, in this work, a study on the interference effect of $\mathrm{CO}_{3}^{2-}$ and $\mathrm{CN}^{-}$on the chemical speciation of $\mathrm{Cr}$ (III) and $\mathrm{Cr}$ (VI) has been done with low and high resolution ICP-MS coupled with $\mathrm{IC}$.

The effect of $\mathrm{CO}_{3}{ }^{2-}$ on the chemical speciation of $\mathrm{Cr}(11 \mathrm{l})$ and $\mathrm{Cr}(\mathrm{VI})$. If the $\mathrm{CO}_{3}{ }^{2-}$ exists in a sample. the carbon in the $\mathrm{CO}_{3}{ }^{2-}$ ion can form the $\mathrm{ArC}^{-}$in the $\mathrm{Ar}$ plasma, and then the $\mathrm{ArC}^{-}$can interfere with the analysis of $\mathrm{Cr}$ (mass 52). In this study, the concentration of carbon in a sample was varied from $5 \mathrm{mg} / \mathrm{L}$, to $15 \mathrm{mg} / \mathrm{L}$, to investigate the effect of carbon on the chemical speciation of chromium. Figure 2

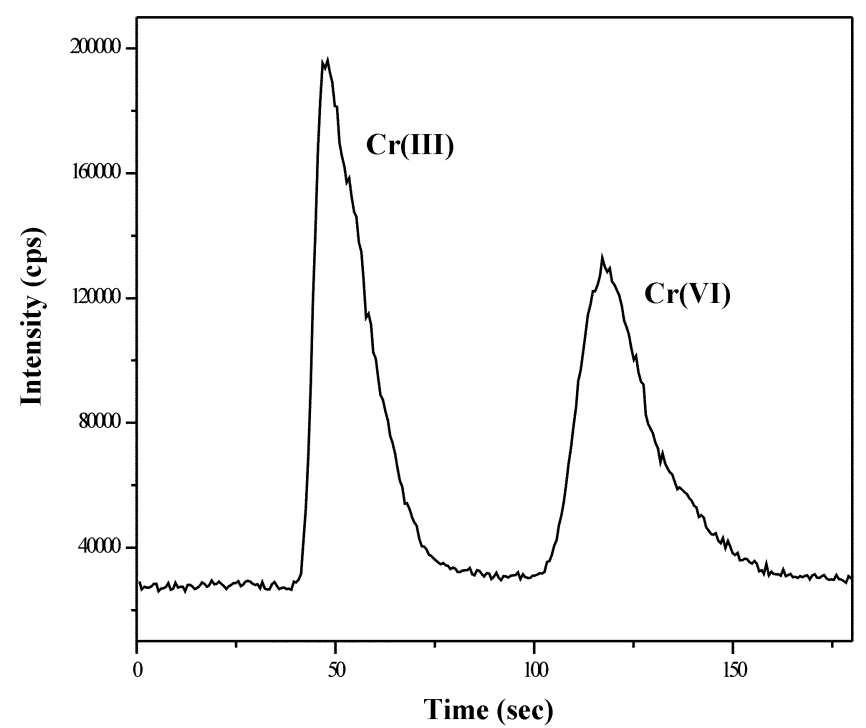

Figure 2, A chromalogram for $10 \mu \mathrm{g} / \mathrm{I}$. $\mathrm{Cr}(\mathrm{III})$ and $\mathrm{Cr}(\mathrm{VI})$ in 0.001 $\mathrm{M}$ IINO, including carbonate ion ( $\left.\mathrm{CO}_{3}{ }^{2-}\right)$ with ICP-MS and IC. (Concentration of carbon: $5 \mathrm{mg} / \mathrm{L}$ ). Eluent: $0.06 \mathrm{M} \mathrm{HVO}$. Resolution: 300 . 


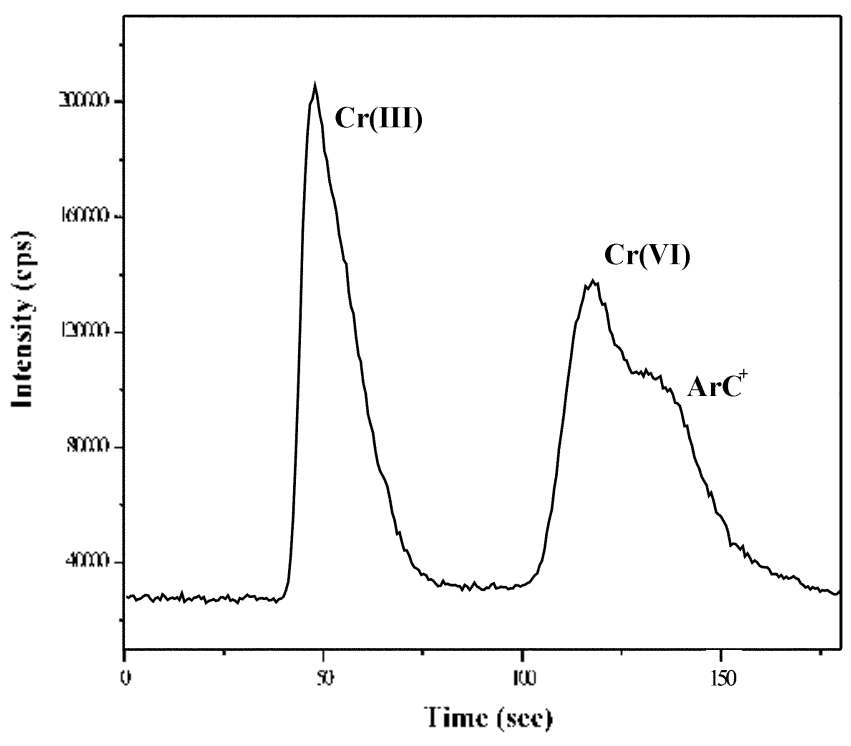

Figure 3. A chromalogram for $10 \mu \mathrm{g} / \mathrm{L}$. Cr(III) and $\mathrm{Cr}(\mathrm{VI})$ in 0.001 $\mathrm{M}^{\mathrm{IINO}} \mathrm{In}_{3}$ including carbonate ion $\left(\mathrm{CO}_{3^{2}}{ }^{2}\right)$ with ICP-MS and $\mathrm{IC}$. (Concentration of carbon: $15 \mathrm{mgL}$ ). Li]uent: $0.06 \mathrm{M} \mathrm{HNO}_{3}$. Resolution: 300.

shows the chromatogram for $10 \mu \mathrm{g} / \mathrm{Cr}(\mathrm{Il})$ and $\mathrm{Cr}(\mathrm{VI})$ in $0.001 \mathrm{M} \mathrm{HNO}_{3}$ including carbonate ion $\left(\mathrm{CO}_{3}{ }^{2-}\right)$. The concentration of carbon was $5 \mathrm{mg} / \mathrm{L}$. The employed mass resolution was 300 , which is typically used for quadrupole ICP-MS. As the results show, the carbon concentration of 5 $\mathrm{mg} / \mathrm{l}$, did not have a serious effect on the speciation of $\mathrm{Cr}(\mathrm{III})$ and $\mathrm{Cr}(\mathrm{VI})$. Figure 3 shows the chromatogram for $10 \mu \mathrm{g} / 1 . \mathrm{Cr}(1 \mathrm{ll})$ and $\mathrm{Cr}(\mathrm{Vl})$ in $0.001 \mathrm{M} \mathrm{HNO}_{s}$ including carbonate ion $\left(\mathrm{CO}_{3^{2}}{ }^{2-}\right)$. The concentration of carbon was $15 \mathrm{mg} / \mathrm{l}$. The result showed that the $\mathrm{ArC}^{-}$did seriously interfere with the determination of $\mathrm{Cr}(\mathrm{VI})$. As the concentration of carbon in a sample was increased, the determination

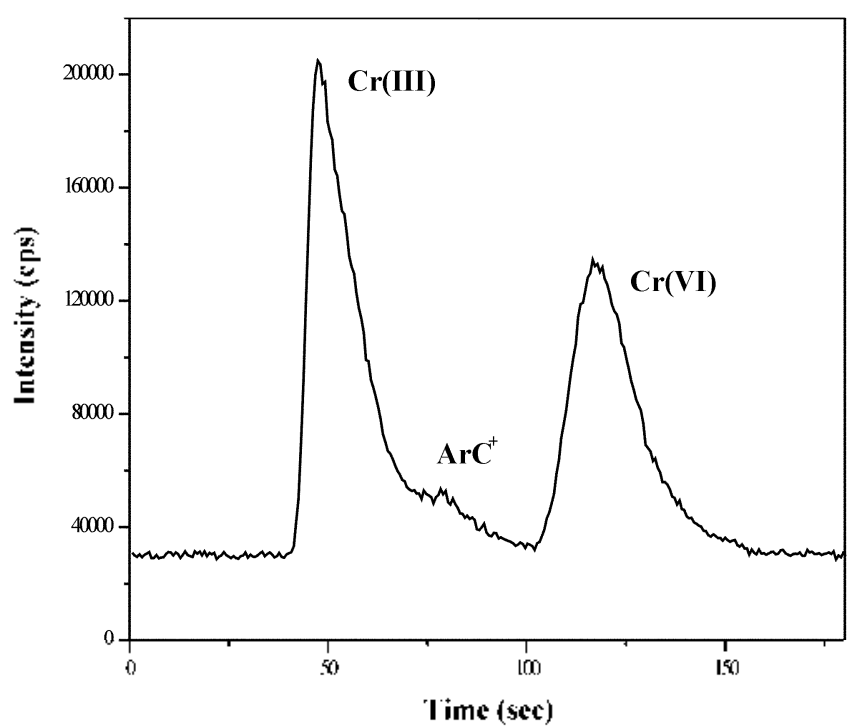

Figure 4. A chromalogram for $10 \mu \mathrm{g} / \mathrm{C}$. Cr(III) and Cr(VI) in 0.001 $\mathrm{MH} \mathrm{NO}_{2}$ including carbonate jon $\left(\mathrm{CN}^{-}\right)$with $\mathrm{ICP}-\mathrm{MS}$ and $\mathrm{IC}$. (Concentration of carbon: $5 \mathrm{mg} / \mathrm{L}$ ). Liluent: $0.06 \mathrm{M} \mathrm{HINO}$. Resolution: 300.

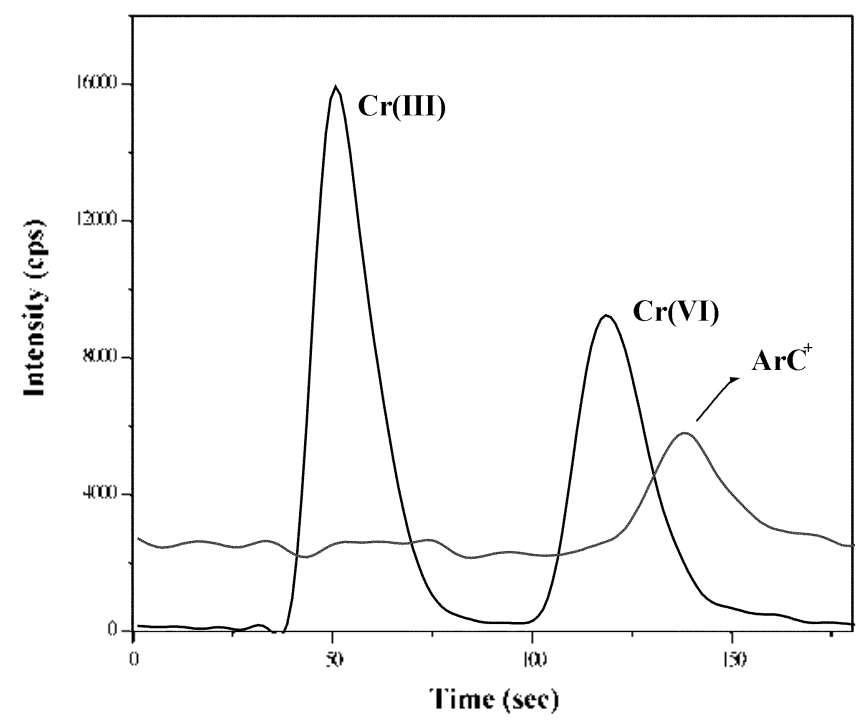

Figure 5. $\Lambda$ chromatogyam for $10 \mu \mathrm{g} / \mathrm{L} \mathrm{Cr}([\mathrm{II})$ and $\mathrm{Cr}(\mathrm{VI})$ in $0.00 \mathrm{l}$ $\mathrm{M} \mathrm{HNO}$ including carbonate ion $\left(\mathrm{CO}_{3}{ }^{2-}\right)$ with ICP-MS and IC. Concentration of carbon: $15 \mathrm{mg} / \mathrm{l}$.). Fluent: $0.06 \mathrm{M} \mathrm{HNO}_{3}$. Resolution: 4000.

of Cr(VI) was not possible. This study shows that the determination of $\mathrm{Cr}$ (VI) can not be done with IC-ICP-MS (mass resolution: 300 ) when the concentration of carbon in a sample is above the $15 \mathrm{mg} / \mathrm{l}$.

The effect of $\mathrm{CN}^{-}$on the chemical speciation of $\mathrm{Cr}$ (III) and $\mathrm{Cr}(\mathrm{VI})$. The carbon in the $\mathrm{CN}^{-}$ion can also form the $\mathrm{ArC}^{+}$in the Ar plasma, then it can possibly interfere with the determination of chromium species. The carbon concentration was varied from $5 \mathrm{mg} / \mathrm{L}$, to $15 \mathrm{mg} / \mathrm{l}$, to investigate the effect of $\mathrm{CN}^{-}$on chemical speciation of chromium. The carbon was originally from the $\mathrm{CN}^{-}$ion in the sample. Figure 4 shows the chromatogram for $10 \mu \mathrm{g} / \mathrm{L}, \mathrm{Cr}(1 \mathrm{ll})$ and $\mathrm{Cr}$ (VI) in $0.001 \mathrm{M} \mathrm{HNO}_{3}$ including cyanide ion $\left(\mathrm{CN}^{-}\right)$with IC-ICP-MS (mass resolution: 300). The concentration of carbon was $5 \mathrm{mg} / \mathrm{L}$. As the results are shown, the formed $\mathrm{ArC}^{+}$from $\mathrm{CN}^{-}$ion interfered with the determination of $\mathrm{Cr}(\mathrm{III})$. Jhis study shows that the $\mathrm{CN}^{-}$ion in a sample can have an interference effect on the determination of $\mathrm{Cr}(\mathrm{III})$ with IC-ICI'-MS (mass resolution: 300) when the concentration of carbon from the $\mathrm{CN}^{-}$ion is above $5 \mathrm{mg} / \mathrm{L}$.

The chemical speciation of $\mathrm{Cr}$ (III) and $\mathrm{Cr}$ (VI) with ICICP-MS (mass resolution: 4000). In this study, the mass resolution of $1 \mathrm{CP}^{2}-\mathrm{MS}$ was increased to reduce or remove the interference by $\mathrm{ArC}^{+}$. Figure 5 shows the chromatogram for $10 \mathrm{mg} / \mathrm{L} \mathrm{Cr}(\mathrm{III})$ and $\mathrm{Cr}(\mathrm{VI})$ in $0.001 \mathrm{M} \mathrm{HNO}_{\mathrm{s}}$ including carbonate ions with IC-ICP-MS (mass resolution: 4000). The concentration of carbon was $15 \mathrm{mg} / \mathrm{L}$. The chromium species (mass 51.9400) could be separated from $\mathrm{ArC}^{-}$(mass 51.9618 ) with [C-ICP-MS (mass resolution: 4000). Thus, the interference of $\mathrm{ArC}^{-}$could be eliminated. This study shows that the chromium speciation can be successfully performed with $\mathrm{IC}-\mathrm{ICP}-\mathrm{MS}$ (mass resolution: 4000) even though the $\mathrm{CO}_{3}{ }^{2-}$ ions co-exist in samples. Figure 6 shows the chromatogram for $10 \mu \mathrm{g} / \mathrm{L} \mathrm{Cr}(\mathrm{III})$ and $\mathrm{Cr}(\mathrm{VI})$ in $0.001 \mathrm{M} \mathrm{HNO}_{3}$ including cyanide ion $\left(\mathrm{CN}^{-}\right)$. The concentration of carbon 


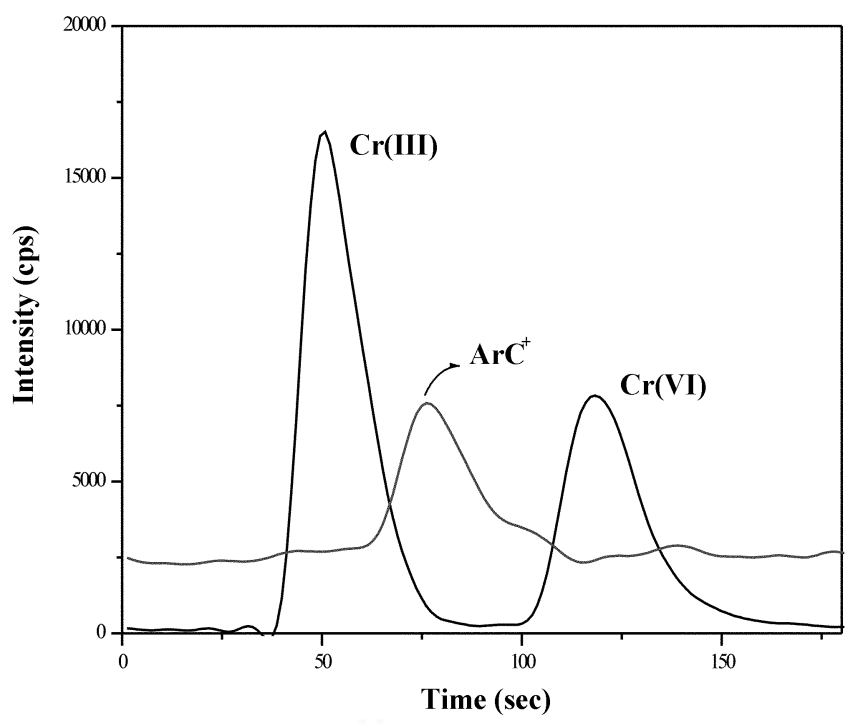

Figure 6. $A$ chromatogram for $10 \mathrm{~kg} \mathrm{~L}(\mathrm{Cr}(\mathrm{III})$ and $\mathrm{Cr}(\mathrm{VI})$ in $0.00 \mathrm{I}$ $\mathrm{M} \mathrm{HNO} 3$ including carbonate ion $\left(\mathrm{CN}^{-}\right)$with $\mathrm{ICP}-\mathrm{MS}$ and IC. (Concentration of carbon: $15 \mathrm{mg} / \mathrm{l}$ ). F.luent: $0.06 \mathrm{M} \mathrm{HNO}$. Resolution: 4000 .

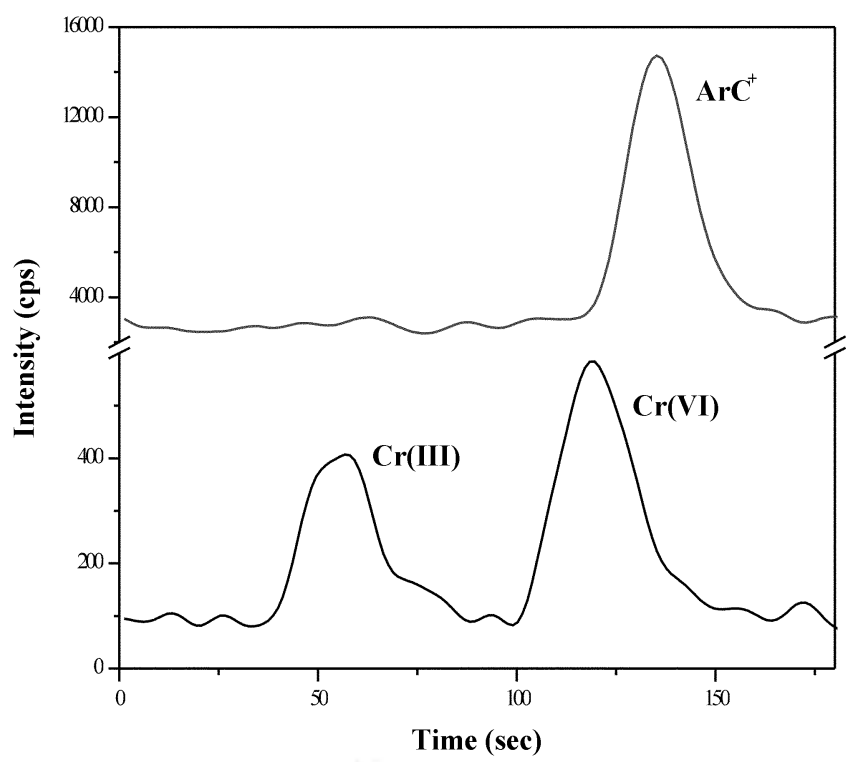

Figure 7. $A$ chromalogram for $\mathrm{Cr}(\mathrm{III})$ and $\mathrm{Cr}(\mathrm{V} I)$ in groundwater with ICP-MS and IC. Lluent: $0.06 \mathrm{M}$ IINO $\mathrm{N}_{3}$. Resolution: 4000.

was $15 \mathrm{mg} / \mathrm{L}$. The result shows that the mass spectral interference of $\mathrm{ArC}^{+}$formed from $\mathrm{CN}^{-}$could be eliminated with IC-JCl'MS (mass resolution: 4000). The chemical speciation of $\mathrm{Cr}(\mathrm{III})$ and $\mathrm{Cr}$ (VI) could be performed with ICICP-MS even if $\mathrm{CN}^{-}$ions exists in the sample.

The determination of $\mathrm{Cr}(\mathrm{III})$ and $\mathrm{Cr}$ (VI) in ground water. The above results show that IC-ICP-MS (mass resolution: 300) could not quantitatively determine the $\mathrm{Cr}(I I I)$ and $\mathrm{Cr}(\mathrm{VI})$ due to the mass spectral interference of $\mathrm{ArC}^{-}$formed from $\mathrm{CO}_{3}^{2-}$. The ground water, in general, contained the $\mathrm{CO}_{3}{ }^{2-}$ ions. Thus, IC-ICP-MS (mass resolution: 4000) was used for the determination of $\mathrm{Cr}(\mathrm{III})$ and $\mathrm{Cr}(\mathrm{VI})$ in a ground water sample. The ground water was

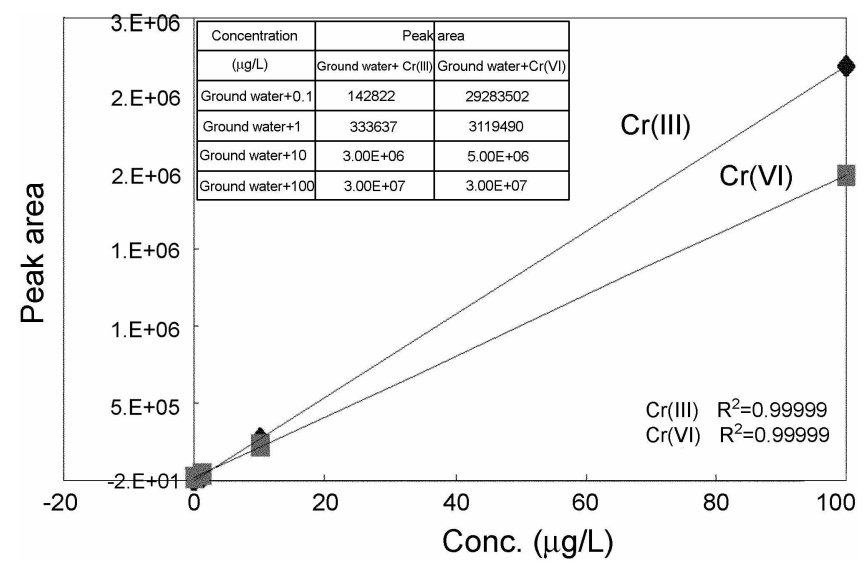

Figure 8. Calibration curve for $\mathrm{Cr}(\mathrm{III})$ and $\mathrm{Cr}(\mathrm{VI})$ in groundwater with IC-ICP-MS. Eluent: $0.06 \mathrm{~V}$ IINO ${ }_{3}$. Resolution: 4000.

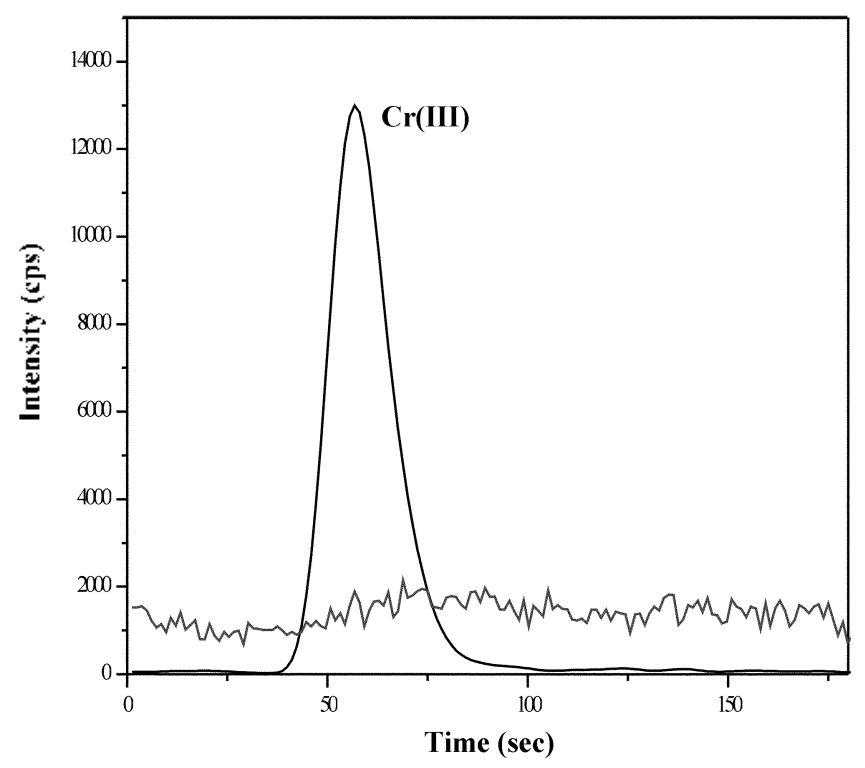

Figure 9. A chromalogram for Cr(III) in NISI SRM I6431 with ICP-MS and IC'. Eluent: $0.06 \mathrm{M}$ IINO ;. Resolution: 4000.

obtained from a site at the Korea Atomic Energy Research Institute, Daejeon, South Korea. Figure 7 shows the chromatogram for the speciation of $\mathrm{Cr}(I I])$ and $\mathrm{Cr}(\mathrm{VI})$ in a ground water with IC-ICP-MS (mass resolution: 4000). The quantitative determination of $\mathrm{Cr}(\mathrm{III})$ and $\mathrm{Cr}(\mathrm{VI})$ was done by the standard addition method. The calibration curves of standard addition method were obtained with [C-IC]-MS (Imass resolution: 4000 ). The results are shown in Figure 8 . the measured concentration of $\mathrm{Cr}(\mathrm{IIJ})$ and $\mathrm{Cr}(\mathrm{V} I)$ were $0.17 \mu \mathrm{g} / \mathrm{L}$ and $0.87 \mu \mathrm{g} / \mathrm{L}$, respectively.

The determination of $\mathrm{Cr}(\mathrm{III})$ and $\mathrm{Cr}(\mathrm{VI})$ in a NIST SRM I643d water sample. IC-ICP-MS (mass resolution: 4000 ) was used to quantitatively determine the $\mathrm{Cr}$ (III) and Cr(VI) in a NIS [ SRM $1643 \mathrm{~d}$. As the results show in Figure 9, the $\mathrm{Cr}$ (III) was detected only in the SRM 1643d. The $\mathrm{Cr}(\mathrm{VI})$ and $\mathrm{ArC}^{-}$were not detected in the SRM 1643d. The measured value is $19.43 \pm 0.41 \mu \mathrm{g} / \mathrm{L}$, which closely matches with the certified value of $19.05 \pm 0.57 \mathrm{ug} / \mathrm{L}$ (total chromium). 


\section{Conclusion}

This study shows that the $\mathrm{CO}_{3}{ }^{2-}$ and $\mathrm{CN}^{-}$ions can interfere with the simultaneous determination of $\mathrm{Cr}$ (III) and $\mathrm{Cr}(\mathrm{VI})$ in a sample with IC-ICP-MS. In particular. IC-ICPMS with low resolution (resolution of 300) is limited for the chemical speciation of $\mathrm{Cr}(\mathrm{III})$ and $\mathrm{Cr}(\mathrm{VI})$ due to the mass spectral interference of $\mathrm{ArC}^{-}$formed by $\mathrm{CO}_{3}{ }^{3-}$ and $\mathrm{CN}^{-}$. Thus, interference problems can be solved by IC-ICP-MS with high resolution (resolution of 4000 ). The method was applied to a ground water sample and an NIST SRM 1643d water sample. The measured concentrations of $\mathrm{Cr}$ (III) and $\mathrm{Cr}(\mathrm{VI})$ were $0.17 \mu \mathrm{g} / \mathrm{L}$ and $0.87 \mu \mathrm{g} / \mathrm{L}$. respectively. in the ground water samples. The $\mathrm{Cr}$ (III) was detected only in a NIST 1643d water sample. The measured value of Cr(III) agrees well with the certified value of total chromium.

\section{References}

1. Trace Metal Analysis and Speciation in Jommat of Chromatograpln Library. Krull. I. S.. Ed.: Elsevier: Amsterdam. 1991: Vol. 47.

2. Trace Metal Analysis and Speciation in Jommal of Chomatographn Librarn: Gjerde. D. T.: Mechra. H.: Krull. I. S.. Eds: Elsevier: Annsterdam. 1991: Vol. 47, pp 213-239.

3. Makata, F.: Hara. S.: Matslo. H.: Kumnamaru, T.: Matsushita. S. Anal. Sci. $1985,1.157$.

4. Urasa. I. T.: Nam. S. J. Chromatogr. Sci. 1989. 127.30.

5. Urasa. I. T.: Ferede. F. Anat. Chem 1987, 59. 1563.

6. Posta, J: Berndt, H: Luo, S. K.; Schaldach. G. Anat. Chent 1993.
65.2590 .

7. Jakubowski. N.: Jepken1s. B.: Stuwer. D.: Berrndt. H. . Anal. Spectront 1994, 9, 193

8. Vidal, J. C.: Sanz, J. M.; Castillo. J. R.: Fresenius, J. Anal Chent 1992. 3H, 234 .

9. Groll. H.: Schaldach. G.: Bemdt. H.: Niemax. K. Spectochim. Acta Part B 1995. 50. 1293.

10. Gjerde. D. T.: Wiederin. D. R.: Smith. F. G.: Mattson. B. M. $J$. Chroantogr: 1993. 640.73.

11. Cox. A. G.: Cook, I. G.; McLoed, C. W. Anahst 1985. 110. 332

12. LaFrenioere, K. E.; Fassel. V. A.: Eckels. D. E. Anal. Chem. 1987. 62.879 .

13. Roychowdhury. S. B.: Koropehak. J. A. Anal. Chom 1990. 62. 484.

14. Lou. S. K.; Berndt. H.; Posta, J. J. Anal Spectront in press.

15. Rochl. R.: Alforque. M. M. At. Spectrose. 1990, 1,210

16. Niemax. K.: Groll. H: Schnurer-Patschan. C. Sipectrochint. Acta Rev 1993.15.349.

17. Jakubowski. N.: Feldmann. I.: Stüwer. D.: Berndt. H. Spectrochim. Acta. Part B 1992. +7. 119

18. Nam. S. H: Kim, M. J.; Oh, S. W.: Lee, J. H.; Pak. Y. N. Anterican Laboratoly $2001,33(8), 40$.

19. Heitkemper, D.; Creed, J: Caruso, J:- Fricke. F. L. J. Anal .At Spectrom 1989. +. 279 .

20. Beauchemin. D.: Siu. K. W. M.: McLaren. J. W.: Beman. S. S. $J$. Anal. At. Spectrom 1989.4 .285$.

21. Branch. S.; Bancroft, K. C. C.: Ebdon. L.; O'Neill, P. Anal. Proc. 1989. 26,73 .

22. Suyani. H.: Heitkemper, D: Creed. J.: Caruso. J. A. Appt. Spectrosc. 1989.43.962.

23. Matz. S. G.: Elder. R. C.: Tepperman. K. J. Anal. At. Spectron. 1989. 4. 767.

24. Nam. S.-H.: Kim. J.-J.; Han, S.-S. Bull. Korean Chent. Soc. 2003. $2+12$. 